\title{
Resistencia a metales pesados y antimicrobianos en cepas de enterococos aisladas de cerdos del Valle Inferior del Río Chubut - Argentina
}

\author{
Resistance to heavy metals and antimicrobial in enterococci strains \\ isolated from pigs of Valle Inferior del Río Chubut - Argentina
}

\begin{abstract}
Vallejo M, Gil M S, Parada RB, Marguet ER. Resistencia a metales pesados y antimicrobianos en cepas de enterococos aisladas de cerdos del Valle Inferior del Río Chubut - Argentina. Rev Colombiana Cienc Anim. Recia. 2020; 12(2):e763. DOI: https://doi.org/10.24188/recia.v12.n2.2020.763

Universidad de Sucre, Colombia
\end{abstract}

Los autores permiten a RECIA reimprimir el material publicado en él. En caso de que un autor quiera traducir o usar una publicación parcial o completa de nuestro Diario, el autor debe obtener un permiso por escrito del editor de la revista.

Copyright (C) 2020. El (los) autor (es), Revista Colombiana de Ciencia Animal - RECIA. 2020. Este es un artículo de acceso abierto distribuido bajo los términos de Creative Commons Attribution 4.0 (https://creativecommons.org/licenses/by-nc-sa/4.0/), El uso, distribución o reproducción está permitido, siempre que se acrediten al autor original y al propietario del copyright y que se cite la publicación original en esta revista, de acuerdo con la práctica académica aceptada. No se permite el uso, distribución o reproducción que no cumpla con estos términos..

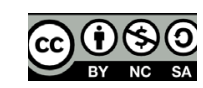




\title{
Resistencia a metales pesados y antimicrobianos en cepas de enterococos aisladas de cerdos del Valle Inferior del Río Chubut - Argentina
}

\author{
Resistance to heavy metals and antimicrobial in enterococci strains isolated from pigs \\ of Valle Inferior del Río Chubut - Argentina
}

Marisol Vallejo* Ph.D.

Universidad Nacional de la Patagonia San Juan Bosco (UNPSJB). Facultad de Ciencias Naturales y Ciencias de la Salud (FCNyCS)-Sede Trelew, Laboratorio de Biotecnología Bacteriana. Argentina.

soltrelew@gmail.com

(iD http://orcid.org/0000-0002-4393-3615

\section{Marianela S. Gil}

Universidad Nacional de la Patagonia San Juan Bosco (UNPSJB). Facultad de Ciencias Naturales y Ciencias de la Salud (FCNyCS)-Sede Trelew, Laboratorio de Biotecnología Bacteriana. Argentina.

gilmarianela4@gmail.com

(iD) http://orcid.org/0000-0002-8754-905X

\section{Romina B. Parada. Lic}

Universidad Nacional de la Patagonia San Juan Bosco (UNPSJB). Facultad de Ciencias Naturales y Ciencias de la Salud (FCNyCS)-Sede Trelew, Laboratorio de Biotecnología Bacteriana. Argentina.

Consejo Nacional de Investigaciones Científicas y Técnicas (CONICET). Argentina.

parada.ro91@gmail.com

(iD) http://orcid.org/0000-0002-1089-9625

Emilio R. Marguet. Ph.D.

Universidad Nacional de la Patagonia San Juan Bosco (UNPSJB). Facultad de Ciencias Naturales y Ciencias de la Salud (FCNyCS)-Sede Trelew, Laboratorio de Biotecnología Bacteriana. Argentina.

emarguet@yahoo.com.ar

(iD) http://orcid.org/0000-0002-9790-8511

Recepción: 2 abril 2020 Aprobación: 5 junio 2019 Publicación: 8 junio 2020

\section{RESUMEN}

El objetivo de este trabajo fue determinar la presencia de factores de virulencia, resistencia a metales pesados y antibióticos en 65 cepas de Enterococcus aisladas del contenido fecal de cerdos, recolectadas en el Valle Inferior del Río Chubut. La producción de exopolisacáridos fue el factor de virulencia más frecuente y se detectó en 45 cepas, mientras que la actividad de gelatinasa se presentó en una sola cepa; el mismo resultado se obtuvo para la actividad hemolítica. La prueba en agar reveló que 25 cepas presentaron resistencia a zinc ( $\geq 12 \mathrm{mM})$ mientras que 64 exhibieron resistencia intermedia a cobre (4-12 mM). Todas las cepas seleccionadas en función de su resistencia al zinc exhibieron resistencia a tetraciclina, dos de ellas a vancomicina y solo una a teicoplanina. Todas las cepas seleccionadas resultaron sensibles a la ampicilina. Mediante PCR se obtuvo la amplificación del gen tetM en 22 cepas que mostraron resistencia a la tetraciclina. Los resultados obtenidos en este estudio evidenciarían el uso generalizado de zinc y tetraciclina como promotores de crecimiento en la alimentación de cerdos. Esta práctica ejerce una presión selectiva en especies bacterianas animales y contribuye a la propagación de la resistencia a los antibióticos.

Palabras clave: Promotores del crecimiento; tetraciclina; alimentación animal; resistencia a antibióticos; zinc. 


\begin{abstract}
The objective of this work was to determine the presence of virulence factors, heavy metal resistance and antibiotic in 65 Enterococcus strains isolated from fecal content of pigs, collected in the Valle Inferior del Río Chubut. Exopolysaccharides production was the most frequent virulence factor and was detected in 45 strains, while gelatinase activity was displayed by only one strain; same result was obtained for hemolytic activity. Agar plates test revealed that 25 strains were resistant to zinc $(\geq 12 \mathrm{mM}$ ) while 64 strains exhibited intermediate copper resistance (4-12 mM). All strains selected on the basis of their resistance to zinc exhibited resistance to tetracycline, two of them resistance to vancomycin and only one resistance to teicoplanin. All strains selected were sensitive to ampicillin. PCR techniques allowed the amplification of tetM gen in 22 strains among the 25 that showed resistance to tetracycline. The results obtained in this study would evidence the widespread usage of zinc and tetracycline as growth promoters in pig feeding. This practice exerts selective pressure in animal bacterial species and contributes to the spread of antibiotic resistance.
\end{abstract}

Keywords: growth promoters, tetracycline, animal feed, antibiotic resistance, zinc

\title{
INTRODUCCIÓN
}

El empleo de antibióticos a partir de la década de 1940, con el propósito de aumentar la producción ganadera y avícola, ha influido en el desarrollo de resistencias. En 1951 la FDA (United States Food and Drug Administration) aprobó el uso de antibióticos en alimentos para animales sin necesidad de prescripción veterinaria (1).

En el ámbito de la producción, se utilizan antimicrobianos para el tratamiento de las infecciones en animales de forma individual o colectiva. Los tratamientos pueden ser profilácticos, metafiláctico y/o terapéuticos según las necesidades. Adicionalmente, en las producciones intensivas de bovinos, cerdos, aves y en acuicultura, se emplean bajas dosis de antimicrobianos como agentes promotores del crecimiento con el fin de acelerar su crecimiento y con ello el rendimiento de la producción (2). Algunos de los antibióticos utilizados en la producción ganadera son de importancia para la salud humana, entre ellos se destacan los macrólidos, tetraciclinas, fluoroquinolonas y cefalosporinas. El uso sin control y/o prescripción veterinaria ha generado graves consecuencias; la administración de dosis sub-terapéuticas durante largo tiempo crea las condiciones necesarias para desarrollar resistencia a antimicrobianos en bacterias comensales y zoonóticas (1).

Desde hace varias décadas, se ha demostrado que las adiciones de zinc y cobre inorgánico en el alimento mejoran el crecimiento de lechones post-destete (2). La industria global porcina utiliza, en combinación o individualmente, altas concentraciones de óxido de Zn (2.000 a 3.000 ppm Zn) y/o sulfato de Cu (125 a 250 ppm Cu) (3,4). Gran parte de estos oligoelementos ingeridos por las diversas especies domésticas (hasta el $99 \%$ ) no es retenida y aparece en heces y orina (5). La emisión de elementos traza al medio ambiente aumenta la polución, especialmente en el caso del Cu y del Zn, un problema que puede reducirse mediante la inclusión juiciosa de los minerales en la dieta.

La resistencia a los antimicrobianos y metales pesados (MP), es la clave para la supervivencia bacteriana en ambientes contaminados. Muchos genes de resistencia a antibióticos y MP están ubicados en los mismos elementos genéticos móviles (2). Dentro de las bacterias prevalentes en estos ambientes perturbados, el género Enterococcus es uno de los más estudiados y representativos. Su extrema ubicuidad le permite habitar distintos nichos ecológicos, incluido el contenido intestinal del hombre y animales; también pueden ser aislados del suelo, agua, plantas e insectos (6).

Este género constituye en la actualidad un grave problema de salud pública debido al desarrollo de resistencia a antimicrobianos y factores de virulencia, donde se destacan la actividad gelatinasa, hemolítica y formación de sustancias de agregación. Estos microorganismos exhiben una alta prevalencia dentro de los ambientes hospitalarios y presentan, cada vez con mayor frecuencia, problemas terapéuticos (7). Exceptuando el ambiente relacionado con la salud, existe escasa información en la región patagónica sobre las características y distribución geográfica de las cepas de enterococos $(8,9)$. Tampoco existen estudios sobre la vía de transmisión de estos microorganismos, resultando necesario una continua vigilancia para conocer si la transmisión ocurre vía cadena alimentaria o se genera en el medio ambiente por actividades antrópicas. En consecuencia, resulta perentorio conocer el estado actual de este problema para contar en el futuro con la posibilidad de realizar estudios retrospectivos que permitan afirmar o rechazar la hipótesis de una eventual transferencia.

El objetivo de este trabajo fue determinar la resistencia a MP (cobre y zinc) en cepas del género Enterococcus aisladas de cerdos de criadero del Valle Inferior del Río Chubut (VIRCh) y su relación con la resistencia a antimicrobianos de uso habitual en la producción animal. 


\section{MATERIALES Y MÉTODOS}

Área geográfica y toma de muestras. La toma de muestras del estudio se llevó a cabo en dos establecimientos porcinos de cría intensiva y ciclo completo localizados en las ciudades de Dolavon y Rawson, ubicadas en el Valle inferior del Río Chubut (VIRCh) provincia de Chubut - Argentina, durante los meses de febrero a abril de 2015. El muestreo se realizó de forma aleatoria a partir de animales sanos, incluyendo adultos y crías de destete en el establecimiento de la ciudad de Rawson, mientras que en el establecimiento de Dolavon todas las muestras provinieron de cerdas en gestación. Las muestras de hisopados fecales se conservaron en medio de transporte Stuart (Merck, Alemania) a $4^{\circ} \mathrm{C}$ hasta el momento de su procesamiento. El tiempo transcurrido entre la colecta y su procesamiento no fue mayor de $6 \mathrm{~h}$.

Aislamiento, selección e identificación preliminar de cepas de enterococos. Las muestras se sembraron en caldo púrpura de bromocresol-azida (Merck, Alemania) y/o en caldo etil violeta azida (Difco, Estados Unidos). Luego de 24 h de incubación a 37ํㅡ los cultivos se repicaron en agar bilis esculina (Merck, Alemania), suplementado con ácido nalidíxico $(20 \mu \mathrm{g} / \mathrm{ml})$ y nistatina $(10 \mu \mathrm{g} / \mathrm{ml})$. Todas las muestras se incubaron a $37^{\circ} \stackrel{\mathrm{C}}{ }$ durante $24-48 \mathrm{~h}$ y se realizaron repiques sucesivos en agar bilis esculina con el objetivo de obtener aislamientos puros.

Posteriormente, la identificación de las colonias sospechosas se realizó mediante la coloración de Gram, ensayo de la actividad catalasa y oxidasa, crecimiento a $45^{\circ} \mathrm{C}$ y $10^{\circ} \mathrm{C}$ y actividad de pirrolidonil aminopeptidasa (Pyr-A-Enterococos, Britania, Argentina).

Los aislamientos identificados como Enterococcus spp. se conservaron a $-30^{\circ} \mathrm{C}$ en una suspensión de caldo tripticasa soja (TS) (Britania, Argentina) suplementado con glicerol al 10\% (v/v) y forman parte de la colección del Cepario del Laboratorio de Biotecnología Bacteriana FCNyCS (Sede Trelew-UNPSJB).

\section{Determinación de factores de virulencia}

Actividad de la gelatinasa. Se realizó en agar TS suplementado con $0.8 \%(\mathrm{~m} / \mathrm{v})$ de gelatina. Las placas se incubaron durante $48 \mathrm{~h}$ a $37^{\circ} \mathrm{C}$ y se revelaron con una solución de ácido tricloroacético al $20 \%$ (v/v). Las zonas claras alrededor de las cepas se consideraron como positivas.

Actividad hemolítica. La producción de hemolisinas se evaluó en agar cerebro-corazón (Biokar, Francia) suplementado con sangre desfibrinada humana 5\%, luego de una incubación a 37ํㅡ durante 48 h. Los resultados se interpretaron como positivos cuando se observó un halo de hemólisis completa alrededor de las colonias ( $\beta$-hemólisis).

Producción de exopolisacáridos. La producción de exopolisacáridos (EPS) de las cepas de enterococos se evaluó de manera cualitativa en agar cerebro-corazón adicionado con sacarosa 50 g/l y $0.8 \mathrm{~g} / \mathrm{l}$ de rojo Congo. Las placas se incubaron a $37^{\circ} \mathrm{C}$ durante $24 \mathrm{~h}$ y el resultado se interpretó como positivo cuando se observaron colonias de color negro (10).

Resistencia a cobre y zinc. Los ensayos de susceptibilidad al cobre y zinc se llevaron a cabo por el método de dilución en agar propuesto por Aarestrup y Hasman (11). Para tal fin se utilizó el agar Mueller-Hinton (Britania, Argentina) al cual se le adicionaron concentraciones crecientes entre $2-28 \mathrm{mM}$ de sulfato de cobre pentahidratado $\left(\mathrm{CuSO}_{4} \cdot 5 \mathrm{H}_{2} \mathrm{O}\right)(\mathrm{Cicarelli}$ Laboratorios, Argentina) y entre $0.25-32 \mathrm{mM}$ de sulfato de zinc heptahidratado $\left(\mathrm{ZnSO}_{4} \cdot 7 \mathrm{H}_{2} \mathrm{O}\right)$ (Cicarelli Laboratorios, Argentina). Las soluciones de cobre y zinc se prepararon en agua destilada, se esterilizaron mediante filtración por membrana $(0.22 \mu \mathrm{m})$ y se almacenaron a $4^{\circ} \mathrm{C}$ hasta su uso.

Todas las placas se inocularon con $5 \mu \mathrm{l}$ de cultivos bacterianos ajustados a 0.5 en la escala de McFarland y se incubaron durante $48 \mathrm{~h}$ a $37^{\circ} \mathrm{C}$. Los resultados se interpretaron como positivos cuando se observó desarrollo de las colonias.

Identificación fenotípica. La identificación fenotípica a nivel de especie de las cepas resistentes a MP se realizó mediante pruebas bioquímicas y fermentación de azúcares, según las recomendaciones de Manero y Blanch (12).

Sensibilidad a antimicrobianos. En todas las cepas que exhibieron resistencia a MP se determinó su concentración inhibitoria mínima (CIM) para ampicilina, tetraciclina y vancomicina mediante el método de las diluciones seriadas, según las recomendaciones del National Committee for Clinical Laboratory Standards Institute (CLSI)-VET (13), mientras que para teicoplanina se utilizaron las recomendaciones del CLSI para antimicrobianos de uso humano (14). La sensibilidad a los antimicrobianos se evaluó por el método de dilución en agar Mueller-Hinton, las placas se incubaron durante 20-24 h a 37ํㅡ y se utilizó la cepa de Enterococcus faecalis ATCC 29212 como microorganismo de control. La CIM se definió como la menor concentración de antibiótico que produce la inhibición completa del microorganismo. 
Detección de genes de resistencia a tetraciclina. Las cepas seleccionadas sobre la base de su resistencia a tetraciclina se incubaron a $37^{\circ} \mathrm{C}$ en caldo TS, durante $16 \mathrm{~h}$. Luego, los cultivos se centrifugaron a 12,000 g durante 5 min y el ADN se extrajo utilizando un equipo comercial de purificación Wizard Genomics Promega (Madison, Wisconsin, EE. UU.) siguiendo las instrucciones del fabricante.

La amplificación del gen tetM se realizó de acuerdo al protocolo sugerido por Aarestrup et al (15). La reacción se llevó a cabo en un termociclador Mastercycler ${ }^{\circledR}$ (Eppendorf, Hamburgo, Alemania). La electroforesis de los productos de la amplificación genética se realizó en gel de agarosa al 1.5\%, a $70 \mathrm{~V}$ durante 1 h en buffer TAE (tris, ácido acético, EDTA, pH 8). Luego de finalizada la corrida, el gel se colocó durante 20 min en una solución de buffer TAE y bromuro de etidio de $0.5 \mu \mathrm{g} / \mathrm{ml}$; posteriormente se visualizó con luz UV en un transiluminador Labsystem ${ }^{\circledR}$ (Geno Technology Inc., EE. UU.), se fotografió y se archivó.

\section{RESULTADOS}

Se procesaron 50 muestras de materia fecal proveniente de ganado porcino de un establecimiento de la ciudad de Rawson y 44 muestras de otro localizado en la ciudad de Dolavon, ambos ubicados en la zona del VIRCh (Chubut-Argentina). Del primer establecimiento se aislaron 37 cepas del género Enterococcus (27 de ejemplares adultos y 10 de cría de destete), mientras que del segundo se aislaron 28 cepas de hembras en gestación. Todas las cepas aisladas y conservadas presentaron los rasgos fenotípicos que distinguen al género Enterococccus de otros cocos Gram-positivos: catalasa y oxidasa negativo, crecimiento a 10 y $45^{\circ} \mathrm{C}$ y Pirrolidonil-beta-naftilamina positivo.

La mayor prevalencia de los factores de virulencia estudiados correspondió a la producción de EPS, detectada en 45 cepas, mientras que una cepa exhibió actividad de gelatinasa y sólo otra resultó $\beta$-hemolítica. La actividad hemolítica como gelatinasa se presentó en cepas de E. faecalis y E. faecium respectivamente, mientras que la producción de EPS se encontró extendida en las diferentes especies aisladas (datos no mostrados).

Mediante la técnica de dilución en agar, 25 cepas resultaron resistentes a zinc ( $\geq 12$ mM), que fueron seleccionadas para su posterior identificación fenotípica y resistencia a antimicrobianos (Tabla 1); mientras que 64 presentaron un patrón de resistencia intermedio al cobre (4-12 mM) (datos no mostrados). Para la determinación de cepas resistentes y/o tolerantes a estos metales se tomó como referencia los puntos de corte propuestos por Aarestrup y Hasman (11) y Hasman et al (4), respectivamente.

Todas las cepas que resultaron resistentes a zinc se identificaron mediante la clave dicotómica propuesta por Manero y Blanch (12), un esquema de reacciones bioquímicas que permite la clasificación de los miembros del género Enterococcus a nivel de especie. Del total de cepas, 18 se clasificaron como E. faecium, 4 como E. columbae, 2 como E. faecalis y 1 como E. durans/hirae (Tabla 1).

Tabla 1. Resistencia a cobre y zinc en cepas de Enterococcus spp. aisladas de cerdos

\begin{tabular}{|c|c|c|c|c|c|c|c|c|c|c|}
\hline \multirow{2}{*}{ Metal pesado } & \multicolumn{9}{|c|}{ № de aislamientos con CIM (mM) } & \multirow{2}{*}{$\begin{array}{c}\text { Resistencia } \\
\mathbf{n} / \mathbf{N} \\
\end{array}$} \\
\hline & 2 & 4 & 8 & 12 & 16 & 20 & 24 & 28 & 32 & \\
\hline \multicolumn{11}{|l|}{ Cobre $(\leq 2-\geq 28)^{a}$} \\
\hline E. faecium (18) & & 1 & 2 & 15 & & & & & & $0 / 18$ \\
\hline E. columbae (4) & & & & 4 & & & & & & $0 / 4$ \\
\hline E. faecails (2) & & & 1 & 1 & & & & & & $0 / 2$ \\
\hline E. durans/hirae (1) & & & 1 & & & & & & & $0 / 1$ \\
\hline \multicolumn{11}{|l|}{$\operatorname{Zinc}(\leq 4-\geq 12)^{b}$} \\
\hline E. faecium (18) & & & & & & & & & 18 & $18 / 18$ \\
\hline E. columbae (4) & & & & & & & & & 4 & $4 / 4$ \\
\hline E. faecails (2) & & & & & & & & & 2 & $2 / 2$ \\
\hline E. durans/hirae (1) & & & & & & & & & 1 & $1 / 1$ \\
\hline
\end{tabular}

a Puntos de corte según Hasman et al (4); ${ }^{2} \leq 2$ : sensible, 4-24: intermedio, $\geq 28$ : resistente

b Punto de corte según Aarestrup y Hasman (11); $\leq 4$ : sensible; $\geq 12$ : resistente 
Las 25 cepas seleccionadas según su resistencia a Zinc resultaron además resistentes a la tetraciclina mediante la

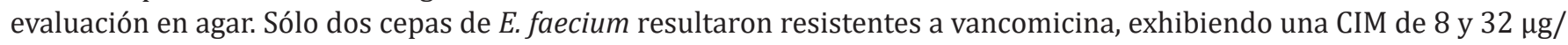
$\mathrm{mL}$, mientras que solo una de estas cepas presentó resistencia a teicoplanina. Todas las cepas de enterococos resultaron sensibles a ampicilina (Tabla 2). Del total de microorganismos resistentes a zinc, 23 resultaron productores de EPS, una cepa de E. faecalis presentó actividad de gelatinasa, mientras que solo un aislado de E. faecium resultó hemolítica.

Tabla 2. Resistencia a antimicrobianos en cepas de Enterococcus spp. aisladas de cerdos

\begin{tabular}{|c|c|c|c|c|c|c|c|c|c|c|c|c|}
\hline \multirow{2}{*}{ Antibiótico } & \multicolumn{11}{|c|}{$\mathrm{N}^{\circ}$ de aislamientos con CIM $(\mu \mathrm{g} / \mathrm{mL})$} & \multirow{2}{*}{$\begin{array}{c}\text { Resistenci } \\
\text { n/N }\end{array}$} \\
\hline & 0,5 & 1 & 2 & 4 & 8 & 12 & 16 & 20 & 24 & 28 & 32 & \\
\hline \multicolumn{13}{|l|}{$\operatorname{Ampicilina}^{1}(\leq 8-\geq 16)^{a}$} \\
\hline E. faecium (18) & 1 & 1 & 2 & 9 & 5 & & & & & & & $0 / 18$ \\
\hline E. columbae (4) & & & 1 & 3 & & & & & & & & $0 / 4$ \\
\hline E. faecails (2) & & & 1 & 1 & & & & & & & & $0 / 2$ \\
\hline E. durans/hirae (1) & 1 & & & & & & & & & & & $0 / 1$ \\
\hline \multicolumn{13}{|c|}{ Teicoplanina $^{2}(\leq 8-\geq 32)^{\mathrm{b}}$} \\
\hline E. faecium (18) & 15 & 2 & & & & & & & & & 1 & $1 / 18$ \\
\hline E. columbae (4) & 4 & & & & & & & & & & & $0 / 4$ \\
\hline E. faecails (2) & 2 & & & & & & & & & & & $0 / 2$ \\
\hline E. durans/hirae (1) & 1 & & & & & & & & & & & $0 / 1$ \\
\hline \multicolumn{13}{|l|}{$\operatorname{Tetraciclina~}^{3}(\leq 4-\geq 16)^{\mathrm{a}}$} \\
\hline E. faecium (18) & & & & & & & 18 & & & & & $18 / 18$ \\
\hline E. columbae (4) & & & & & & & 4 & & & & & $4 / 4$ \\
\hline E. faecails (2) & & & & & & & 2 & & & & & $2 / 2$ \\
\hline E. durans/hirae (1) & & & & & & & 1 & & & & & $1 / 1$ \\
\hline \multicolumn{13}{|l|}{$\operatorname{Vancomicina}^{4}(\leq 4-\geq 8)^{\mathrm{a}}$} \\
\hline E. faecium (18) & & 9 & 1 & 6 & 1 & & & & & & 1 & $2 / 18$ \\
\hline E. columbae (4) & & 2 & 1 & 1 & & & & & & & & $0 / 4$ \\
\hline E. faecails (2) & & 1 & 1 & & & & & & & & & $0 / 2$ \\
\hline E. durans/hirae (1) & & & & 1 & & & & & & & & $0 / 1$ \\
\hline
\end{tabular}

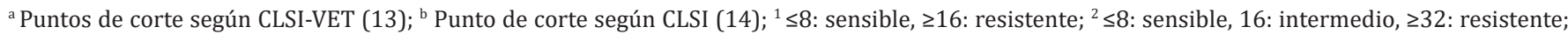
${ }^{3} \leq 4$ : sensible, 8 : intermedio, $\geq 16$ : resistente; ${ }^{4} \leq 4$ : sensible, 8-16: intermedio, $\geq 32$ : resistente.

Del total de cepas seleccionadas, 21 presentaron un amplicón de 657 pb compatible con el gen de resistencia a tetraciclina tet $M$, mientras que en 4 cepas de E. faecium no se obtuvo amplificación (datos no mostrados).

\section{DISCUSIÓN}

Históricamente la producción porcina en la provincia del Chubut fue de baja escala, de tipo familiar, en zonas bajo riego y destinada básicamente a la producción de lechones estacionales, elegida como secundaria a otras actividades agropecuarias. Sin embargo, desde hace un tiempo se observa un crecimiento de la actividad porcina en toda la provincia, especialmente en la zona del VIRCh. La mayor parte de los establecimientos del valle se caracterizan por ser una explotación de tipo familiar, destinada al consumo propio y local. En las ciudades de Rawson y Dolavon, pertenecientes a la mencionada zona, existen dos establecimientos productores de gran escala empresarial, de ciclo completo quienes han integrado a su producción intensiva un sistema eficiente, incorporando genética, faenando de manera formal y realizando su propia comercialización.

Los 65 aislamientos obtenidos de Enterococcus spp., a partir de 94 muestras de materia fecal provenientes de los establecimientos porcinos, demuestran la alta frecuencia de este género en este nicho. Los enterococos y las enterobacterias son microorganismos comensales que se utilizan con frecuencia como indicadores biológicos en programas de vigilancia y seguimiento, porque proporcionan información sobre el posible reservorio de genes de resistencia a los agentes antimicrobianos, que podrían transferirse a bacterias patógenas (16).

Los resultados obtenidos sobre frecuencia de actividad gelatinasa y hemolítica fueron inferiores si los comparamos con el estudio realizado por Ledesma et al (9) en cepas de Enterococcus spp. aisladas de aves salvajes y de cría de la región 
patagónica. Sin embargo, los enterococos son reconocidos por su plasticidad genómica, son capaces de integrar elementos móviles como plásmidos, transposones y secuencias de inserción que les permite adquirir fácilmente determinantes genéticos entre cepas de la misma especie o especies del mismo género. Además, ciertos factores de virulencia y la resistencia a antimicrobianos (RAM) son conocidos por estar asociados con plásmidos altamente transmisibles (17).

La producción de EPS está relacionada con la capacidad de formar biofilm y la posibilidad de colonizar superficies inertes utilizadas habitualmente en clínica (18). Según los resultados obtenidos en este estudio y en trabajos previos (10,19), este rasgo está ampliamente distribuido y es independiente de la especie. Sin embargo, sería prematuro clasificar a una cepa de enterococo como patógena sólo evaluando este rasgo. En el futuro se debería estudiar otros factores de patogenicidad relacionados con la producción de EPS, como la sustancia de agregación, cuya presencia incrementa considerablemente la adherencia a los túbulos renales, a células intestinales e internalización enterocóccica en los macrófagos (18).

Del total de microorganismos aislados, 25 cepas presentaron resistencia a zinc ( $\geq 12 \mathrm{mM})$ y patrones intermedios a cobre (4-12 mM). Estos resultados son similares a los obtenidos por Nezhad Fard et al (2) y Aarestrup y Hasman (11), quienes relacionan ambas resistencias con elementos genéticos móviles. Tanto el cobre como el zinc son ampliamente utilizados como promotores del crecimiento en la cría intensiva de cerdos en diferentes concentraciones (4). En consecuencia, como una respuesta natural, muchas especies bacterianas han desarrollado mecanismos de resistencia para sobrevivir en presencia de estos MP. Estudios previos han reportado que la resistencia a zinc y a antibióticos están vinculados en los mismos elementos genéticos móviles (20), contribuyendo de esta manera a la diseminación de resistencia a MP en especies bacterianas de origen animal debido a la presión selectiva impuesta por el uso de antibióticos y viceversa.

El uso de agentes antimicrobianos como promotores del crecimiento fue prohibido en todos los países de la Unión Europea (UE) en el año 2006, sin embargo todavía se los utiliza para el tratamiento en animales (6). En particular, la tetraciclina se utiliza para el tratamiento de enfermedades en cerdos, práctica que induce la proliferación de resistencia (21). En la actualidad las tetraciclinas no se utilizan con frecuencia para el tratamiento de infecciones humanas, sin embargo su uso inadecuado puede ejercer una presión selectiva sobre los enterococos generando resistencia a otros antimicrobianos (vancomicina y gentamicina) (6).

En nuestro país, en el año 2010 se realizó el primer estudio sobre los patrones de resistencia a antimicrobianos en bacterias indicadoras y zoonóticas provenientes de muestras fecales de animales sanos. En el caso particular de los porcinos se encontró que, de 43 aislamientos de Enterococcus spp. el $92.8 \%$ resultó resistente a tetraciclina, mientras que no se detectó resistencia a ampicilina (22). No obstante a la iniciativa del Servicio Nacional de Sanidad y Calidad Agroalimentaria implementada mediante la resolución 591/2015 (23) y dirigida a la concientización y control de RAM en animales destinados al consumo humano, la Argentina no cuenta con un programa de vigilancia permanente en establecimientos agropecuarios.

Además de la resistencia a Zn, las 25 cepas seleccionadas de Enterococcus spp. presentaron resistencia a tetracilina, mientras que dos cepas de E. faecium exhibieron resistencia a vancomicina ( $\geq 8 \mu \mathrm{g} / \mathrm{mL}$ ). Estos dos aislamientos, clasificados como E. faecium, deberían en el futuro someterse a estudios genéticos con el propósito de evaluar si la resistencia que presentan es de tipo adquirida y transferible (vanA/vanB) o intrínsica (vanC). Ninguna de las cepas seleccionadas resultó resistente a ampicilina, resultado que tiene un valor predictivo de sensibilidad para amoxicilina, amoxicilina-clavulánico, ampicilina sulbactam y piperacilina-tazobactam en enterococos no productores de betalactamasas (13).

Los resultados obtenidos en el presente trabajo sobre la presencia de genes tet $M$ de resistencia a tetraciclina en cepas de enterococos coincide con otros estudios previos realizados en explotaciones animales $(2,24)$, presentándose como la resistencia más extendida entre las bacterias.

La relación entre animales de consumo y emergencia de RAM en salud humana ha sido documentada claramente en bacterias zoonóticas como Salmonella spp. y Campylobacter spp. (22). Las resistencias han aparecido también en bacterias comensales presentes en el tracto intestinal de los animales, tales como Enterococcus spp. y Escherichia coli, las que pueden ser transmitidas por los alimentos y actuar como reservorios de genes de resistencia, transfiriéndolos a bacterias patógenas o zoonóticas de importancia para la salud pública.

Los resultados obtenidos en este estudio demuestran la incidencia de resistencia a zinc y a tetraciclina en cepas de enterococos de origen porcino. Si bien estas bacterias no son causa frecuente de infecciones en animales, pueden ser reservorios de genes de resistencia y diseminarse a otras bacterias, las que sí pueden causar infecciones en animales y en el hombre. 
Teniendo en cuenta la escasa o nula información en nuestro país y especialmente en la zona del VIRCh sobre RAM en bacterias indicadoras y zoonóticas en animales domésticos y de cría, los resultados obtenidos en este estudio podrían considerarse como punto de partida en futuros programas de monitoreo.

\section{Conflicto de intereses}

No existen conflictos de intereses, incluyendo entre estos últimos las relaciones financieras, personales o de otro tipo con otras personas u organizaciones que pudieran influir de manera inapropiada en el trabajo.

\section{Financiación}

Este trabajo fue financiado con fondos otorgados por la Secretaría de Ciencia y Técnica de la Universidad Nacional de la Patagonia San Juan Bosco (Proyecto de Investigación № 1531).

\section{REFERENCIAS}

1. Ardoino S, Toso R, Toribio M, Álvarez H, Mariani E, Cachau P, et al. Antimicrobianos como promotores de crecimiento (AGP) en alimentos balanceados para aves: uso, resistencia bacteriana, nuevas alternativas y opciones de reemplazo. Cienc Vet. 2017; 19(1):50-66. https://doi.org/10.19137/cienvet-20171914

2. Nezhad Fard, RM Heuzenroeder M, Barton M. Antimicrobial and heavy metal resistance in commensal enterococci isolated from pigs. Vet Microbiol. 2011; 148:276-282. https://doi.org/10.1016/j.vetmic.2010.09.002

3. Vahjen W, Pietruszyńska D, Starke I, Zentek J. High dietary zinc supplementation increases the occurrence of tetracycline and sulfonamide resistance genes in the intestine of weaned pigs. Gut Pathog. 2015; 7:23. https://doi. org/10.1186/s13099-015-0071-3

4. Hasman H, Kempf I, Chidaine B, Cariolet R, Ersbøll A, Houe H, et al. Copper resistance in Enterococcus faecium, mediated by the tcrB gene, is selected by supplementation of pig feed with copper sulfate. Appl Env Microbiol. 2006; 72(9):5784-5789. https://doi.org/10.1128/aem.02979-05

5. Zea O, Vílchez C. Efecto de la suplementación con fuentes de cobre sobre el comportamiento productivo, morfometría intestinal y nivel de cobre hepático en pollos de carne. Rev Investig Vet Peru. 2014; 25(1):16-28. http://www.scielo. org.pe/scielo.php?script=sci_arttext\&pid=S1609-91172014000100002

6. Hammmerum A. Enterococci of animal origin and their significance for public health. Clin Microbiol Infect. 2012; 18(7):619-625. https://doi.org/10.1111/j.1469-0691.2012.03829.x

7. Sharifi Y, Abedzadeh A, Salighe A, Kalhor N, Khodadad Motlagh, M Javadi A. Antibiotics and heavy metals resistance patterns of Enterococcus faecalis and faecium bacteria isolated from the human and the livestock sources. Environ Heal Eng Manag J. 2015; 2(4):199-202. http://ehemj.com/browse.php?a id=125\&sid=1\&slc lang=en

8. Vallejo M, Ledesma P, Ibañez C, Aguirre L, Parada R, Vallejo B, et al. Resistencia a metales pesados, antibióticos y factores de virulencia en cepas de Enterococcus aisladas en la provincia del Chubut Argentina. RSVM. 2016; 36:1622. http://ve.scielo.org/scielo.php?script=sci arttext\&pid=S1315-25562016000100005

9. Ledesma P, Parada R, Vallejo M, Marguet E. Factores de virulencia de cepas de Enterococcus aisladas de aves silvestres y de corral en la Patagonia. Analecta Vet. 2015; 35(1):6-12. http://www.fcv.unlp.edu.ar/images/stories/analecta/ vol 35 n1/264_Ledesma.pdf

10. Ciftci A, Findik A, İça T, Bas B, Onuk E, Güngördü S. Slime production and antibiotic resistance of Enterococcus faecalis isolated from arthritis in chickens. J Vet Sci Med. 2009; 71:849-853. https://doi.org/10.1292/jvms.71.849 
11. Aarestrup F, Hasman H. Susceptibility of different bacterial species isolated from food animals to copper sulphate, zinc chloride and antimicrobial substances used for disinfection. Vet Microbiol. 2004; 100(1-2):83-89. https://doi. org/10.1016/j.vetmic.2004.01.013

12. Manero A, Blanch A. Identification of Enterococcus spp. with a biochemical key. J Appl Env Microbiol. 1999; 65(10):4425-30. https://doi.org/10.1128/AEM.65.10.4425-4430.1999

13. Clinical and Laboratory Standards Institute-VET. Performance standards for antimicrobial disk and dilution susceptibility test for bacteria isolated from animals, $5^{\text {th }}$ ed. CLSI standard vet01 Wayne PA: Cl Clinical and Laboratory Standards Institute; 2018. https://clsi.org/media/2325/vet01ed5_sample.pdf

14. Clinical and Laboratory Standards Institute. Performance standards for antimicrobial Susceptibility testing; $28^{\text {th }}$ ed. CLSI supplement M100. Table 2E. Zone Diameter and MIC Breakpints for Enterococcus spp. Wayne PA: Clinical and Laboratory Standards Institute; 2018. https://clsi.org/media/1930/m100ed28 sample.pdf

15. Aarestrup FM, Agerso Y, Gerner-Smidt P, Madsen M, Jensen LB. Comparison of antimicrobial resistance phenotypes and resistance genes in Enterococcus faecalis and Enterococcus faecium from humans in the community, broilers, and pigs in Denmark. Diagn Microbiol Infect Dis 2000; 37(2):127-137. https://doi:10.1016/s0732-8893(00)00130-9

16. Organización Mundial de Sanidad Animal (OIE). Código Sanitario para los Animales Terrestres (Vol. I). $2^{\text {nd }}$ ed. Organización Mundial De Sanidad Animal: Francia; 2013. https://www.oie.int/doc/ged/D12823.PDF

17. Igbinosa EO, Beshiru A. Antimicrobial resistance, virulence determinants, and biofilm formation of Enterococcus species from ready-to-eat seafood. Front Microbiol. 2019; 10:728. https://doi.org/10.3389/fmicb.2019.00728

18. Ch'ng J, Chong K, Lam L, Wong J, Kline K. Biofilm-associated infection by enterococci. Nat Rev Microbiol. 2018; 17(2):82-94. https://doi.org/10.1038/s41579-018-0128-7

19. Tsikrikonis G, Maniatis A, Labrou M, Ntokou E, Michail G, Daponte A, et al. Differences in biofilm formation and virulence factors between clinical and fecal enterococcal isolates of human and animal origin. Microb Pathog. 2012; 52(6):336-343. https://doi.org/10.1016/j.micpath.2012.03.003

20. Li L, Xia Y, Zhang T. Co-occurrence of antibiotic and metal resistance genes revealed in complete genome collection. ISME J. 2016; 11(3):651-662. https://doi.org/10.1038/ismej.2016.155

21. Hao H, Sander P, Iqbal Z, Wang Y, Cheng G, Yuan Z. The risk of some veterinary antimicrobial agents on public health associated with antimicrobial resistance and their molecular basis. Front Microbiol. 2016; 7:16-26. https://dx.doi. org/10.3389\%2Ffmicb.2016.01626

22. Pantozzi F, Moredo F, Vigo G, Giacoboni I. Resistencia a los antimicrobianos en bacterias indicadoras y zoonóticas aisladas de animales domésticos en Argentina. Rev Argent Microbiol. 2010; 42:49-52. http://sedici.unlp.edu.ar/ bitstream/handle/10915/70634/Documento completo.pdf-PDFA.pdf?sequence=1\&isAllowed=y

23. SENASA. Programa Nacional de Vigilancia de resistencia a los antimicrobianos en los animales destinados a consumo humano. Res. 591/2015. Ministerio de Agricultura, Ganadería y Pesca: Argentina; 2015. http://www.senasa.gov.ar/ sites/default/files/normativas/archivos/res 591-2015.pdf

24. Tan S, Chong C, Ju Teh C, Ooi P, Thong K. Occurrence of virulent multidrug-resistant Enterococcus faecalis and Enterococcus faecium in the pigs, farmers and farm environments in Malaysia. Peer J. 2018; 6:e5353. https://doi. org/10.7717/peerj.5353 